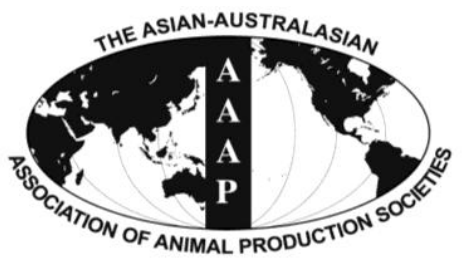

Asian-Aust. J. Anim. Sci.

Vol. 25, No. $8: 1169$ - 1177

August 2012

www.ajas.info

http://dx.doi.org/10.5713/ajas.2012.12085

\title{
Growth Performance, Meat Quality and Fatty Acid Metabolism Response of Growing Meat Rabbits to Dietary Linoleic Acid
}

\author{
R. G. Li, X. P. Wang, C. Y. Wang, M. W. Ma and F. C. Li* \\ College of Animal Science and Technology, Shandong Agricultural University, Tai'an, Shandong, 271018, China
}

\begin{abstract}
An experiment was conducted to determine the effects of different amounts of dietary linoleic acid (LA) on growth performance, serum biochemical traits, meat quality, fatty acids composition of muscle and liver, acetyl-CoA carboxylase (ACC) and carnitine palmitoyl transferase 1 (CPT 1) mRNA expression in the liver of 9 wks old to 13 wks old growing meat rabbits. One hundred and fifty 9 wks old meat rabbits were allocated to individual cages and randomly divided into five groups. Animals in each group were fed with a diet with the following LA addition concentrations: 0, 3, 6, 9 and $12 \mathrm{~g} / \mathrm{kg}$ diet (as-fed basis) and LA concentrations were 0.84, $1.21,1.34,1.61$ and $1.80 \%$ in the diet, respectively. The results showed as follows: the dietary LA levels significantly affected muscle color of LL included $a^{*}$ and $b^{*}$ of experimental rabbits $(\mathrm{p}<0.05)$. The linear effect of LA on serum high density lipoprotein cholesterol was obtained $(\mathrm{p}=0.0119)$. The saturated fatty acids (SFAs) and monounsaturated fatty acids (MUFAs) contents of LL decreased and the polyunsaturated fatty acids (PUFAs) content of LL increased with dietary LA increase $(p<0.0001)$. The PUFA n- 6 content and PUFA n-3 content in the LL was significantly affected by the dietary LA levels $(p<0.01, p<0.05)$. The MUFAs content in the liver decreased and the PUFAs contents in the liver increased with dietary LA increase ( $p<0.0001)$. The PUFA $n-6$ content and the PUFA $n-6 / n-3$ ratio in the liver increased and PUFA n-3 content in the liver decreased with dietary LA increase $(p<0.01)$. The linear effect of LA on CPT 1 mRNA expression in the liver was obtained $(\mathrm{p}=0.0081)$. In summary, dietary LA addition had significant effects on liver and muscle fatty acid composition (increased PUFAs) of 9 wks old to 13 wks old growing meat rabbits, but had little effects on growth performance, meat physical traits and mRNA expression of liver relative enzyme of experimental rabbits. (Key Words: Growing Meat Rabbit, Linoleic Acid, Growth Performance, Meat Quality, Fatty Acid, mRNA Expression)
\end{abstract}

\section{INTRODUCTION}

The relationship between dietary fatty acid (FA) composition and meat FA profile had been widely and well assessed in the last 40 years. As reviewed by Xiccato (1999), Dalle Zotte (2002), Cavani et al. (2009), Dalle Zotte and Szendro (2011), it is well-known that meat FA proportion of fat depots and intramuscular fat composition greatly changes as a result of dietary FA composition. Meanwhile, there are many scientific papers dealing with the use of polyunsaturated fatty acid (PUFA) $\mathrm{n}-6$ rich diet in rabbits and its effect on live performances and meat quality traits (Cobos et al., 1995; Lopez-Bote et al., 1997; Oliver et al., 1997). At least during the last 10 years, research has been focused to develop feeding strategies aiming to increase the value of rabbit meat as a "functional food", including in rabbit diets n-3 PUFA, conjugated linoleic acid (CLA),

\footnotetext{
* Corresponding Author: F. C. Li. Tel: +86-0538-8242593-8319, Fax: +86-0538-8241419, E-mail: chlf@sdau.edu.cn Submitted Feb. 14, 2012; Accepted May 1, 2012; Revised May 7, 2012
}

vitamins and antioxidants, etc. According to Food and Agriculture Organization/World Health Organization (FAO/WHO), it is essential to increase the $n-3$ and decrease the $n-6$ fatty acid intake in order to have a balanced $n-6$ and n-3 intake (Simopoulos, 2008).

Standard rabbit meat is already a quite good source of unsaturated fatty acids (UFA) and linoleic acid (LA) (DAlle Zotte and Szendro, 2011) because it represents about 60\% and $22 \%$ of total FAs, respectively. Rabbit meat can be effectively used to produce functional meat and meat products, since manipulation of the rabbit diet is very effective in increasing the levels of n-3 PUFA or CLA (Corino et al., 2002, 2003; Kouba et al., 2008; Tres et al., 2008). This was due to the largely commercial use of sunflower and soybean in the diet of rabbits. As a consequence, from a nutritional points of view it is more interesting PUFA n-3 enrichment of rabbit meat (Dal Bosco et al., 2004; Bianchi et al., 2006; Kouba et al., 2008; Peiretti and Meineri, 2008; Bianchi et al., 2009), while PUFA n-6 incorporation can be merely interesting from a scientific 
point of view (e.g. effect on live performance, lipogenic enzyme activity, etc.).

The objectives of the present study were to investigate and discuss the effects of LA on growth performance, meat quality, serum biochemical traits, muscle and liver fatty acids composition in growing meat rabbits. In addition, the effects of dietary LA concentration on acetyl-CoA carboxylase (ACC) and carnitine palmitoyl transferase 1 (CPT 1) mRNA expression in the liver were also determined.

\section{MATERIALS AND METHODS}

\section{Animals and diets}

One hundred and fifty crossbred rabbits of New Zealand white rabbits $\times$ local white rabbits ( 9 wks old) were allocated to five groups and there were 30 rabbits in each group (male and female had half each). Rabbits were individually housed in self-made metabolism cages $(60 \times 40 \times 40 \mathrm{~cm})$. The rabbits had free access to water. During the trials, rabbits were housed in a closed and ventilated building in which the maximum temperature is $5^{\circ} \mathrm{C}$ and the minimum temperature is $-5^{\circ} \mathrm{C}$ (winter) and the relative humidity ranges from $50 \%$ to $60 \%$. A cycle of $12 \mathrm{~h}$ of light and $12 \mathrm{~h}$ of dark was used throughout this trial.

The diets were formulated according to the values to growing from NRC (1977) and de Blas and Mateos (1998) and were pelleted by the use of pressure (Table 1). The diameter of the pellets was $4 \mathrm{~mm}$. The LA addition concentrations of the five experimental diets were $0,3,6,9$ and $12 \mathrm{~g} / \mathrm{kg}$ diet (as-fed basis) and LA concentrations were $0.84,1.21,1.34,1.61$ and $1.80 \%$ in the diet, respectively.

\section{Experimental procedures}

The experiment lasted for 4 wks which included 1 wk adaptation period and 3 wks experimental period. Feeds were provided ad libitum and the feeder was refilled at 8:30 and 17:30 daily. The residual feed in the raising cages was collected daily.

Individual weight was measured after the one week adaptation and the end of the trial and the average daily gain (ADG) was calculated. The average daily feed intake (ADI) was calculated according to total of food intake divided by 3 wks experimental period, and feed to gain (F/G) ratio were calculated. The ADG, ADI, and F/G calculation did not include the 7-d adjustment period.

At the end of the trial, 40 rabbits ( 8 rabbits per group, male and female had half each, and the average body weight of the 8 rabbits equals to the average body weight of entire treatment group) were selected, the rabbits were electrically stunned $(70 \mathrm{~V}$, pulsed direct current, $50 \mathrm{~Hz}$ for 5 s) and $10 \mathrm{ml}$ of blood was collected immediately from the heart and the rabbits were killed by cervical dislocation $1 \mathrm{~h}$ before dark. The blood samples were kept in the dark at room temperature for $30 \mathrm{~min}$ and then centrifuged at 1,000 $\times \mathrm{g}$ for $10 \mathrm{~min}$. The serum was placed into an Eppendorf tube

Table 1. Ingredients and chemical composition of the experimental diets

\begin{tabular}{|c|c|c|c|c|c|}
\hline \multirow{2}{*}{ Ingredient $(\mathrm{g} / \mathrm{kg}$ diet $)$} & \multicolumn{5}{|c|}{ Linoleic acid concentrations in the diet $(\mathrm{g} / \mathrm{kg})$} \\
\hline & 0 & 3 & 6 & 9 & 12 \\
\hline Corn & 249.8 & 241.05 & 232.3 & 218.55 & 204.8 \\
\hline Soybean meal & 160 & 160 & 160 & 160 & 160 \\
\hline Wheat bran & 180 & 180 & 180 & 180 & 180 \\
\hline Peanut vine & 380 & 385 & 390 & 400 & 410 \\
\hline Ethyl linoleate $^{\mathrm{a}}$ & 0 & 3.75 & 7.5 & 11.25 & 15 \\
\hline $\mathrm{CaHPO}_{4}$ & 15 & 15 & 15 & 15 & 15 \\
\hline Salt & 5 & 5 & 5 & 5 & 5 \\
\hline Antioxidant & 0.2 & 0.2 & 0.2 & 0.2 & 0.2 \\
\hline Premix $^{b}$ & 10 & 10 & 10 & 10 & 10 \\
\hline \multicolumn{6}{|c|}{ Chemical composition (Calculated, \%) } \\
\hline Digestible energy $(\mathrm{MJ} / \mathrm{kg})$ & 10.41 & 10.45 & 10.48 & 10.48 & 10.48 \\
\hline Crude protein & 15.80 & 15.78 & 15.76 & 15.75 & 15.75 \\
\hline Crude fiber & 13.59 & 13.72 & 13.85 & 14.12 & 14.39 \\
\hline Methionine+cysteine & 0.45 & 0.45 & 0.45 & 0.45 & 0.45 \\
\hline Lysine & 0.56 & 0.56 & 0.56 & 0.56 & 0.56 \\
\hline $\mathrm{Ca}$ & 0.59 & 0.59 & 0.59 & 0.59 & 0.59 \\
\hline$P$ & 0.54 & 0.54 & 0.54 & 0.54 & 0.54 \\
\hline Linoleic acid (Analyzed) & 0.84 & 1.21 & 1.34 & 1.61 & 1.80 \\
\hline
\end{tabular}

${ }^{a}$ Ethyl linoleate came from Beijing Haoersi Technology Co., Ltd. and the content of linoleic acid was $80.6 \%$.

${ }^{\mathrm{b}}$ The premix provides following for a kilogram of diet: VA, 8,000 IU; VD3, 1,000 IU; VE, $50 \mathrm{mg}$; VK, $2 \mathrm{mg}$; lys, 2 g; met, 2 g; Cu, 40 mg; Fe, $100 \mathrm{mg}$; Zn, 50 mg; Mn, 30 mg; I, 0.5 mg; Se, 0.5 mg; Bacitracin zinc, 300 mg. 
and cryopreserved at $-20^{\circ} \mathrm{C}$ for biochemical traits measurement. The hot carcass weight (weight of the carcass 15 to $30 \mathrm{~min}$ after slaughter) and chilled carcass weight (weight of the above carcass after chilling for $24 \mathrm{~h}$ in 0 to $4^{\circ} \mathrm{C}$ after slaughter) were measured.

At slaughtering, liver was removed from each carcass immediately. Meanwhile, the whole longissimus lumborum (LL) (between the $1 \mathrm{st}$ and 7 th lumber vertebra) was removed from the right side of each carcass. LL was then divided into four sub-samples. One of these was used for $\mathrm{pH}$ measurement. On the second and third sub-samples, respectively, the muscle color $\left(\mathrm{L}^{*}, \mathrm{a}^{*}\right.$ and $\left.\mathrm{b}^{*}\right)$, shear force and drip loss percentage were determined at the end of the chilling period $(24 \mathrm{~h}, \mathrm{~d} 1)$. The fourth section of LL, as well as liver were frozen immediately in liquid nitrogen and subsequently stored at $-70^{\circ} \mathrm{C}$ until analyzed for fatty acid composition, ACC and CPT 1 mRNA expression.

\section{Chemical analysis and statistics}

Dressing out percentage and drip loss percentage of the LL were calculated according to the following formulae introduced by Blasco and Ouhayoun (1993): Dressing out percentage $(\%)=$ chilled carcass weight/live weight $\times 100 \%$. Drip loss percentage $(\%)=$ (hot carcass weight-chilled carcass weight)/hot carcass weight (\%). The $\mathrm{pH}$ value was determined from each rabbit 45 min post-mortem and d 1 with a $\mathrm{pH}$ meter equipped with a $\mathrm{pH}$ probe by penetrating 3 $\mathrm{mm}$ into the LL.

Shear force $(\mathrm{kg} \cdot \mathrm{f})$ of the LL was evaluated on cores $(1.25 \times 2 \mathrm{~cm})$ obtained from the mid-portions of the cooked samples (cooked in a water bath at $80^{\circ} \mathrm{C}, 10 \mathrm{~min}$ ) up to $80^{\circ} \mathrm{C}$ internal temperature of the LL by cutting them perpendicular to fiber direction, using the Warner-Blatzler meat shear apparatus (C-LM, USA) (Ouhayoun and Dalle Zotte, 1996). Three samples of per LL were used for shear force measurement and the values were averaged. The color includes $\mathrm{L}^{*}$ (lightness or brightness), $\mathrm{a}^{*}$ and $\mathrm{b}^{*}$ (redness and yellowness) parameters was measured at the muscle surface of the LL using Chromameter type CR-100 (Minolta, Tokyo, Japan).

The automatic biochemical analyzer (Hitachi7020, Japan) was used to analyze serum triglyceride (TG), total cholesterol (TC), high density lipoprotein cholesterol (HDL-C), low density lipoprotein cholesterol (LDL-C) and very low density lipoprotein cholesterol (VLDL-C) following the manual of commercial kits (WAKO, Japan).

The total lipids were extracted from the LL and liver samples by the method of Folch et al. (1957). Eight grams of the sample was homogenized with a $2: 1(\mathrm{v} / \mathrm{v})$ mixture of chloroform-methanol. After standing for $2 \mathrm{~h}$ the lower layer was withdrawn and concentrated in a rotary evaporator in a water bath at $60^{\circ} \mathrm{C}$, under $\mathrm{N}_{2}$ flow. Transmethylation was carried out by a mixture of methanol, benzene and sulphuric acid (75:25:4). Gas chromatography was performed on a Shimadzu GC-2014 (Shimadzu Corp., Tokyo, Japan) apparatus equipped with a DB-23 type capillary column $(0.25 \mathrm{~mm} \times 30 \mathrm{~m} \times 0.25 \mu \mathrm{m})$ and flame ionization detector. Direct injection on the column was performed with $0.25 \mu \mathrm{l}$ samples. Characteristic operating conditions were: the carrier gas was $\mathrm{N}_{2}$ with a flow rate of $24 \mathrm{ml} / \mathrm{min}, \mathrm{H}_{2}$ and air flows to the detector were $60 \mathrm{ml} / \mathrm{min}$. Injector and detector temperatures were $250^{\circ} \mathrm{C}$. The oven temperature was $190^{\circ} \mathrm{C}$. Fatty acids were identified by comparison of the retention times with known standard mixtures of fatty acid methyl esters (NU-VHEK, USA) and quantified by a Shimadzu CRGA integrator (Shimadzu Corp., Tokyo, Japan). Results were expressed as percentage (w/w) of the total fatty acid methyl esters. The analysis was designed to detect the following fatty acids: C14:0, C16:0, C17:0, C18:0, C16:1, C18:1, C18:2 (n-6), C18:3 (n-6), C18:3 (n-3), C20:2 (n-6), C20:3 (n-6), C20:4 (n-6), C20:5 (n-3), C22:4 (n-6), C22:5 $(n-3), C 22: 6(n-3)$.

Total RNA was isolated from liver sample using Trizol reagent (Invitrogen, Carlsbad, CA, USA) following the manufacturer's instructions. The RNA concentration was determined by measuring absorbance at $260 \mathrm{~nm}$. Subsequently, a $2 \mu \mathrm{g}$ of RNA was treated with DNase prior to the reverse transcription to cDNA using a PrimeScript ${ }^{\circledR}$ RT Reagent Kit (Takara, Dalian, China). The cDNA samples were stored at $-20^{\circ} \mathrm{C}$.

To measure expression of ACC and CPT1 mRNA of liver, real-time PCR was performed using a 7500 Real Time PCR System (Applied Biosystems, Carlsbad, CA, USA) and SYBR Premix Ex Taq Kit (Takara, Dalian, China). The volume of each PCR reaction was $50 \mu \mathrm{l}$ which included 4 $\mu \mathrm{l}$ cDNA, $25 \mu \mathrm{l} \mathrm{SYBR}$ Premix Ex Taq, $1 \mu \mathrm{l}$ PCR forward primer, $1 \mu \mathrm{l}$ PCR reverse primer, $1 \mu \mathrm{l}$ ROX Reference Dye II and $18 \mu \mathrm{l} \quad \mathrm{ddH}_{2} \mathrm{O}$. The forward primer (5'TGGCTGTATCCATTATGTCAAGCG-3') and the reverse primer (5'-TGAAGAAAGGGTCAGGAAGGCAGTA-3') were designed according to ACC sequence (Genebank accession No. XM-002719077). The forward primer (5'AGGTGCTCCTCTCCTACCACGG-3') and the reverse primer (5'-GTTGCTGTTCACCATCAGTGGC-3') were designed according to CPT 1 sequence (Genebank accession No. XM-002724092). Glyceraldehyde-3phosphate dehydrogenase (GAPDH) was used as the internal control gene. The forward primer (5'TGCCACCCACTCCTCTACCTTCG-3') and reverse primer (5'-CCGGTGGTTTGAGGGCTCTTACT-3') were designed to amplify the GAPDH gene according to its published sequence (Genebank accession No. RABGLY3PHO). All data were normalized to the internal control GAPDH and the relative expression levels were 
Table 2. The effect of dietary linoleic acid on growth performance of the experimental rabbits $(\mathrm{n}=30)^{*}$

\begin{tabular}{lccccccc}
\hline \multirow{2}{*}{ Items } & \multicolumn{5}{c}{ Linoleic acid concentration in the diet (\%) } & \multirow{2}{*}{ RMSE } & \multirow{2}{*}{$\mathrm{p}^{* *}$} \\
\cline { 2 - 6 } & 0.84 & 1.21 & 1.34 & 1.61 & 1.80 & & 0.8111 \\
Initial weight $(\mathrm{g})$ & 1,683 & 1,634 & 1,690 & 1,622 & 1,700 & 173.6055 & 0.5364 \\
Final weight $(\mathrm{g})$ & 2,010 & 2,006 & 1,963 & 1,934 & 2,010 & 203.1683 & 0.0746 \\
Average daily intake (g/d) & 113 & 113 & 113 & 111 & 111 & 2.9500 & 0.7925 \\
Average daily gain (g/d) & 17.4 & 19.8 & 18.3 & 18.2 & 18.3 & 4.3900 & 0.5733 \\
Feed/gain ratio & 6.49 & 5.87 & 6.39 & 6.55 & 6.28 & 1.0003 & 0.573 \\
\hline
\end{tabular}

* Values are reported as group means, the same in the following tables. ** p value for linear response. RMSE $=$ Root mean square error.

calculated using the $2^{-\Delta \Delta \mathrm{Ct}}$ method.

Linear effect of concentration of LA on all parameters was analyzed by SAS using the regression procedures (1985). Root mean square error (RMSE) and coefficient of determination $\left(\mathrm{R}^{2}\right)$ were used to evaluate the goodness of fit for the different effects.

\section{RESULTS}

\section{Growth performance}

The effect of diet on growth performance is shown in Table 2. The final weight, $\mathrm{ADI}, \mathrm{ADG}$ and $\mathrm{F} / \mathrm{G}$ had no significant differences among different groups ( $p>0.05)$.

\section{Dressing out percentage and meat quality}

As is shown in Table 3, LA concentrations had no significant influence on dressing out percentage, $\mathrm{L}^{*}$ of muscle color of LL, $\mathrm{pH}$ value of 45 min post-mortem and $\mathrm{d}$ 1 , shear force and drip loss percentage of experimental rabbits $(p>0.05)$. LA concentrations had significant influence on muscle color of LL included $a^{*}$ and $b^{*}(p=$ $0.0288, p=0.0003)$. The linear effect of LA on $a^{*}$ was obtained $(\mathrm{p}=0.0288)$ and $\mathrm{a}^{*}$ in the LL of the $0.84 \%$ diet group was the lowest $(\mathrm{p}<0.05)$. The $\mathrm{b}^{*}$ of the LL increased with dietary LA levels increase $(\mathrm{p}<0.01)$.

\section{Serum biochemical traits}

The effect of diet on serum biochemical traits is shown in Table 4. LA concentrations had no significant influence on serum TG, TC, LDL-C and VLDL-C of experimental rabbits ( $p>0.05)$. The linear effect of LA on serum HDL-C was obtained $(\mathrm{p}=0.0119)$ and serum HDL-C in the $0.84 \%$

Table 3. The effect of dietary linoleic acid on dressing out percentage and meat quality of the experimental rabbits $(\mathrm{n}=8)$

\begin{tabular}{|c|c|c|c|c|c|c|c|c|}
\hline \multirow{2}{*}{\multicolumn{2}{|c|}{ Items }} & \multicolumn{5}{|c|}{ Linoleic acid concentration in the diet $(\%)$} & \multirow{2}{*}{ RMSE } & \multirow{2}{*}{$\mathrm{p}^{*}$} \\
\hline & & 0.84 & 1.21 & 1.34 & 1.61 & 1.80 & & \\
\hline \multicolumn{2}{|c|}{ Dressing out percentage (\%) } & 43.7 & 43.6 & 43.0 & 42.7 & 43.0 & 0.0204 & 0.3103 \\
\hline \multirow[t]{3}{*}{ Musclecolor } & $\mathrm{L}^{*}$ & 43.9 & 43.3 & 42.0 & 44.4 & 43.8 & 1.4037 & 0.6540 \\
\hline & $a^{*}$ & $2.14^{\mathrm{c}}$ & $3.41^{\mathrm{b}}$ & $4.13^{\mathrm{a}}$ & $4.43^{\mathrm{a}}$ & $3.88^{\mathrm{ab}}$ & 1.2191 & 0.0288 \\
\hline & $\mathrm{b}^{*}$ & $6.89^{\mathrm{B}}$ & $7.39^{\mathrm{AB}}$ & $7.47^{\mathrm{AB}}$ & $7.84^{\mathrm{A}}$ & $8.00^{\mathrm{A}}$ & 0.5812 & 0.0003 \\
\hline \multicolumn{2}{|c|}{ Shear force $(\mathrm{kg} \cdot \mathrm{f})$} & 2.03 & 2.07 & 1.88 & 1.81 & 2.04 & 0.3452 & 0.4745 \\
\hline \multicolumn{2}{|l|}{$\mathrm{pH}(45 \min )$} & 6.73 & 6.68 & 6.65 & 6.63 & 6.79 & 0.1663 & 0.7468 \\
\hline \multicolumn{2}{|l|}{$\mathrm{pH}(24 \mathrm{~h})$} & 5.90 & 5.96 & 5.92 & 5.85 & 5.88 & 0.0787 & 0.0885 \\
\hline \multicolumn{2}{|c|}{ Drip loss percentage $(\%)$} & 0.10 & 0.10 & 0.08 & 0.09 & 0.09 & 0.0178 & 0.2415 \\
\hline
\end{tabular}

The values with different big letters in the same row differ significantly $(\mathrm{p}<0.01)$. The values with different small letters in the same row differ significantly $(\mathrm{p}<0.05)$.

$\mathrm{RMSE}=$ Root mean square error. $* \mathrm{p}$ value for linear response.

Table 4. The effect of dietary linoleic acid on serum biochemical traits of the experimental rabbits $(\mathrm{mmol} / \mathrm{L})(\mathrm{n}=8)$

\begin{tabular}{|c|c|c|c|c|c|c|c|}
\hline \multirow{2}{*}{ Items } & \multicolumn{5}{|c|}{ Linoleic acid concentration in the diet (\%) } & \multirow{2}{*}{ RMSE } & \multirow{2}{*}{$\mathrm{p}^{*}$} \\
\hline & 0.84 & 1.21 & 1.34 & 1.61 & 1.80 & & \\
\hline Triglyceride & 0.64 & 0.55 & 0.56 & 0.56 & 0.59 & 0.1758 & 0.9876 \\
\hline Total cholesterol & 1.23 & 1.40 & 1.38 & 1.36 & 1.40 & 0.2092 & 0.2740 \\
\hline High density lipoprotein cholesterol & $0.52^{\mathrm{c}}$ & $0.61^{\mathrm{bc}}$ & $0.75^{\mathrm{ab}}$ & $0.86^{\mathrm{a}}$ & $0.68^{\mathrm{abc}}$ & 0.1491 & 0.0119 \\
\hline Low density lipoprotein cholesterol & 0.58 & 0.65 & 0.55 & 0.62 & 0.57 & 0.1200 & 0.6580 \\
\hline Very low density lipoprotein cholesterol & 0.30 & 0.25 & 0.22 & 0.31 & 0.27 & 0.0760 & 0.7321 \\
\hline
\end{tabular}

The values with different small letters in the same row differ significantly $(\mathrm{p}<0.05)$.

$\mathrm{RMSE}=$ Root mean square error. $* \mathrm{p}$ value for linear response. 
Table 5. The effect of dietary linoleic acid on fatty acids composition in the longissimus lumborum (LL) of the experimental rabbits (\%) $(\mathrm{n}=8)$

\begin{tabular}{|c|c|c|c|c|c|c|c|}
\hline \multirow{2}{*}{$\begin{array}{l}\text { Fatty acid composition } \\
\text { (\% of total) }\end{array}$} & \multicolumn{5}{|c|}{ Linoleic acid concentration in the diet $(\%)$} & \multirow{2}{*}{ RMSE } & \multirow{2}{*}{$\mathrm{p}^{*}$} \\
\hline & 0.84 & 1.21 & 1.34 & 1.61 & 1.80 & & \\
\hline C14:0 & $1.82^{\mathrm{A}}$ & $1.80^{\mathrm{A}}$ & $1.57^{\mathrm{AB}}$ & $1.08^{\mathrm{C}}$ & $1.23^{\mathrm{BC}}$ & 0.4055 & 0.0006 \\
\hline $\mathrm{C} 16: 0$ & $29.4^{\mathrm{A}}$ & $28.8^{\mathrm{A}}$ & $27.4^{\mathrm{B}}$ & $25.9^{\mathrm{C}}$ & $25.2^{\mathrm{C}}$ & 0.9654 & $<0.0001$ \\
\hline $\mathrm{C} 17: 0$ & 0.73 & 0.69 & 0.69 & 0.71 & 0.73 & 0.0516 & 0.7674 \\
\hline C18:0 & $7.64^{\mathrm{B}}$ & $7.68^{\mathrm{B}}$ & $8.06^{\mathrm{AB}}$ & $8.67^{\mathrm{A}}$ & $8.14^{\mathrm{AB}}$ & 0.5698 & 0.0078 \\
\hline SFAs & $39.6^{\mathrm{A}}$ & $39.0^{\mathrm{A}}$ & $37.7^{\mathrm{B}}$ & $36.3^{\mathrm{C}}$ & $35.3^{\mathrm{D}}$ & 0.9319 & $<0.0001$ \\
\hline C16:1 & $1.89^{\mathrm{A}}$ & $1.79^{\mathrm{A}}$ & $1.41^{\mathrm{AB}}$ & $1.05^{\mathrm{B}}$ & $1.06^{\mathrm{B}}$ & 0.4653 & 0.0001 \\
\hline C18:1 & $21.9^{\mathrm{A}}$ & $21.3^{\mathrm{AB}}$ & $20.0^{\mathrm{B}}$ & $17.1^{\mathrm{C}}$ & $17.5^{\mathrm{C}}$ & 1.6100 & $<0.0001$ \\
\hline MUFAs & $23.8^{\mathrm{A}}$ & $23.1^{\mathrm{AB}}$ & $21.4^{\mathrm{B}}$ & $18.1^{\mathrm{C}}$ & $18.5^{\mathrm{C}}$ & 1.9772 & $<0.0001$ \\
\hline C18:2 (n-6) & $26.7^{\mathrm{D}}$ & $28.6^{\mathrm{C}}$ & $30.2^{\mathrm{BC}}$ & $31.4^{\mathrm{AB}}$ & $32.9^{\mathrm{A}}$ & 1.6481 & $<0.0001$ \\
\hline C18:3 (n-3) & $0.86^{\mathrm{a}}$ & $0.84^{\mathrm{a}}$ & $0.78^{\mathrm{ab}}$ & $0.61^{\mathrm{c}}$ & $0.70^{\mathrm{b}}$ & 0.1882 & 0.0238 \\
\hline C20:2 (n-6) & 0.44 & 0.37 & 0.39 & 0.36 & 0.37 & 0.0661 & 0.0757 \\
\hline$C 20: 3(n-6)$ & $0.48^{\mathrm{b}}$ & $0.47^{\mathrm{b}}$ & $0.53^{\mathrm{ab}}$ & $0.67^{\mathrm{a}}$ & $0.60^{\mathrm{a}}$ & 0.1626 & 0.0326 \\
\hline $\mathrm{C} 20: 4(\mathrm{n}-6)$ & $6.75^{\mathrm{BC}}$ & $6.31^{\mathrm{C}}$ & $7.74^{\mathrm{ABC}}$ & $10.82^{\mathrm{A}}$ & $9.82^{\mathrm{AB}}$ & 2.6874 & 0.0029 \\
\hline$C 22: 4(n-6)$ & $1.40^{\mathrm{B}}$ & $1.32^{\mathrm{B}}$ & $1.65^{\mathrm{AB}}$ & $2.06^{\mathrm{A}}$ & $2.02^{\mathrm{A}}$ & 0.5585 & 0.0058 \\
\hline PUFAs & $36.7^{\mathrm{C}}$ & $37.9^{\mathrm{C}}$ & $40.9^{\mathrm{B}}$ & $45.6^{\mathrm{A}}$ & $46.2^{\mathrm{A}}$ & 2.4357 & $<0.0001$ \\
\hline PUFA n-6 & $35.77^{\mathrm{C}}$ & $37.07^{\mathrm{C}}$ & $40.51^{\mathrm{B}}$ & $45.31^{\mathrm{A}}$ & $45.71^{\mathrm{A}}$ & 2.2324 & $<0.0001$ \\
\hline PUFA n-3 & $0.86^{\mathrm{a}}$ & $0.84^{\mathrm{a}}$ & $0.78^{\mathrm{ab}}$ & $0.61^{\mathrm{c}}$ & $0.70^{\mathrm{b}}$ & 0.1882 & 0.0238 \\
\hline PUFA n-6/n-3 & $41.59^{\mathrm{B}}$ & $44.13^{\mathrm{B}}$ & $51.94^{\mathrm{B}}$ & $74.28^{\mathrm{A}}$ & $65.30^{\mathrm{A}}$ & 12.5333 & $<0.0001$ \\
\hline
\end{tabular}

\footnotetext{
* p value for linear response.
}

The values with different big letters in the same row differ significantly $(\mathrm{p}<0.01)$. The values with different small letters in the same row differ significantly $(\mathrm{p}<0.05)$.

RMSE $=$ Root mean square error. SFAs $=$ Saturated fatty acid; SFAs $(\%)=$ C14:0+C16:0+C17:0+C18:0;

MUFAs $=$ Monounsaturated fatty acid MUFAs $(\%)=\mathrm{C} 16: 1+\mathrm{C} 18: 1$.

PUFAs = Polyunsaturated fatty acid; PUFAs $(\%)=$ C18:2 (n-6)+C18:3 (n-3)+C20:2 (n-6)+C20:3 (n-6)+C20:4 (n-6)+C22:4 (n-6).

PUFA n-6 $(\%)=$ C18:2 (n-6)+C20:2 (n-6)+C20:3 (n-6)+C20:4 (n-6)+C22:4 (n-6). PUFA n-3 (\%) = C18:3 (n-3). PUFA n-6/n-3 = PUFA n-6/PUFA n-3.

diet group was the lower than those of $1.34 \%$ and $1.61 \%$ diet groups $(\mathrm{p}<0.05)$.

\section{Fatty acids composition in the muscle and liver}

The fatty acids composition in the LL was shown in Table 5. The C14:0, C16:0, C18:0 and SFAs contents in the LL were significantly affected by dietary LA $(p<0.01)$ and the SFAs content of LL decreased with dietary LA increase ( $p<0.0001)$. The $\mathrm{C} 17: 0$ content in the LL had not significant different among different treatments $(p>0.05)$. The $C 16: 1$, C18:1 and MUFAs contents in the LL decreased with dietary LA increase $(\mathrm{p}<0.01)$. The dietary LA levels significantly affected the C18:2 (n-6), C18:3 (n-3), C20:3 (n-6), C20:4 (n-6), C22:4 (n-6) and PUFAs contents in the LL $(\mathrm{p}<0.01, \mathrm{p}<0.05)$, and the PUFAs content in the LL increased with dietary LA increase $(\mathrm{p}<0.0001)$. The PUFA n-6 content and PUFA n-3 content in the LL was significantly affected by the dietary LA levels $(\mathrm{p}<0.01$, $\mathrm{p}<0.05)$. The PUFA $\mathrm{n}-6 / \mathrm{n}-3$ ratio in the $1.61 \%$ and $1.80 \%$ diet groups were higher than those of $0.84 \%, 1.21 \%$ and $1.34 \%$ diet groups $(\mathrm{p}<0.01)$. The differences of C20:2 (n-6) content in the LL of different treatments were not significant $(\mathrm{p}>0.05)$.
The fatty acids composition in the liver was shown in Table 6. Although the dietary LA significantly affected $\mathrm{C} 16: 0, \mathrm{C} 17: 0$ and $\mathrm{C} 18: 0$ contents in the liver $(\mathrm{p}<0.01)$, the SFAs content in the live had not significant different among different treatments $(\mathrm{p}>0.05)$. The $\mathrm{C} 16: 1, \mathrm{C} 18: 1$ and MUFAs contents in the liver were significantly affected by dietary LA $(p<0.01)$ and the MUFAs content in the liver decreased with dietary LA increase $(\mathrm{p}<0.0001)$. The differences of C18:2 (n-6), C18:3 (n-6), C18:3 (n-3), C20:2 (n-6), C20:4 (n-6) and PUFASs contents in the liver were significant $(\mathrm{p}<0.01)$, and the PUFAs contents in the liver increased with dietary LA increase $(\mathrm{p}<0.0001)$. The PUFA $n-6$ content and the PUFA $n-6 / n-3$ ratio in the liver increased and PUFA n-3 content in the liver decreased with dietary LA increase $(\mathrm{p}<0.01)$. The differences of C20:3 (n6) and $C 22: 4$ (n-6) contents in the liver of different treatments were not significant $(\mathrm{p}>0.05)$.

\section{Acetyl-CoA carboxylase and carnitine palmitoyl transferase $1 \mathrm{mRNA}$ expression in the liver}

Table 7 displayed the effects of different amounts of dietary LA on ACC and CPT 1 mRNA expression in the liver. The linear effect of LA on CPT 1 mRNA expression 
Table 6. The effect of dietary linoleic acid on fatty acids composition in the liver of the experimental rabbits $(\%)(\mathrm{n}=8)$

\begin{tabular}{|c|c|c|c|c|c|c|c|}
\hline \multirow{2}{*}{$\begin{array}{l}\text { Fatty acid composition } \\
\text { (\% of total) }\end{array}$} & \multicolumn{5}{|c|}{ Linoleic acid concentration in the diet (\%) } & \multirow{2}{*}{ RMSE } & \multirow{2}{*}{$\mathrm{p}^{*}$} \\
\hline & 0.84 & 1.21 & 1.34 & 1.61 & 1.80 & & \\
\hline$\overline{\mathrm{C} 14: 0}$ & 0.13 & 0.14 & 0.12 & 0.11 & 0.10 & 0.0346 & 0.0525 \\
\hline $\mathrm{C} 16: 0$ & $17.7^{\mathrm{A}}$ & $17.6^{\mathrm{A}}$ & $17.0^{\mathrm{A}}$ & $16.1^{\mathrm{B}}$ & $15.5^{\mathrm{B}}$ & 0.7702 & $<0.0001$ \\
\hline $\mathrm{C} 17: 0$ & $0.89^{\mathrm{C}}$ & $0.98^{\mathrm{BC}}$ & $1.06^{\mathrm{AB}}$ & $1.15^{\mathrm{A}}$ & $1.12^{\mathrm{A}}$ & 0.0707 & $<0.0001$ \\
\hline C18:0 & $23.6^{\mathrm{B}}$ & $24.0^{\mathrm{B}}$ & $25.7^{\mathrm{A}}$ & $25.7^{\mathrm{A}}$ & $25.6^{\mathrm{A}}$ & 1.1253 & 0.0020 \\
\hline SFAs & 42.3 & 42.7 & 43.7 & 43.0 & 42.3 & 0.9180 & 0.9764 \\
\hline C16:1 & $0.56^{\mathrm{A}}$ & $0.37^{\mathrm{B}}$ & $0.27^{\mathrm{BC}}$ & $0.21^{\mathrm{C}}$ & $0.19^{\mathrm{C}}$ & 0.0892 & $<0.0001$ \\
\hline C18:1 & $12.6^{\mathrm{A}}$ & $10.4^{\mathrm{B}}$ & $8.42^{\mathrm{C}}$ & $6.86^{\mathrm{D}}$ & $6.56^{\mathrm{D}}$ & 1.0837 & $<0.0001$ \\
\hline MUFAs & $13.1^{\mathrm{A}}$ & $10.8^{\mathrm{B}}$ & $8.68^{\mathrm{C}}$ & $7.07^{\mathrm{D}}$ & $6.75^{\mathrm{D}}$ & 1.1670 & $<0.0001$ \\
\hline C18:2 (n-6) & $31.0^{\mathrm{C}}$ & $32.1^{\mathrm{BC}}$ & $30.7^{\mathrm{C}}$ & $33.6^{\mathrm{AB}}$ & $35.1^{\mathrm{A}}$ & 1.6103 & 0.0006 \\
\hline C18:3 (n-6) & $0.31^{\mathrm{B}}$ & $0.35^{\mathrm{B}}$ & $0.34^{\mathrm{B}}$ & $0.41^{\mathrm{A}}$ & $0.46^{\mathrm{A}}$ & 0.0881 & 0.0040 \\
\hline $\mathrm{C} 18: 3(\mathrm{n}-3)$ & $0.40^{\mathrm{A}}$ & $0.37^{\mathrm{AB}}$ & $0.31^{\mathrm{BC}}$ & $0.29^{\mathrm{C}}$ & $0.27^{\mathrm{C}}$ & 0.0471 & $<0.0001$ \\
\hline C20:2 (n-6) & $0.90^{\mathrm{A}}$ & $0.96^{\mathrm{A}}$ & $0.81^{\mathrm{AB}}$ & $0.62^{\mathrm{C}}$ & $0.69^{\mathrm{BC}}$ & 0.1285 & 0.0004 \\
\hline C20:3 (n-6) & 0.81 & 0.92 & 1.30 & 1.04 & 1.24 & 0.3246 & 0.0533 \\
\hline C20:4 (n-6) & $9.97^{\mathrm{B}}$ & $10.5^{\mathrm{B}}$ & $12.5^{\mathrm{A}}$ & $12.7^{\mathrm{A}}$ & $11.9^{\mathrm{A}}$ & 0.9691 & 0.0022 \\
\hline C22:4 (n-6) & 1.16 & 1.28 & 1.47 & 1.31 & 1.32 & 0.2041 & 0.3242 \\
\hline PUFAs & $44.6^{\mathrm{C}}$ & $46.6^{\mathrm{B}}$ & $47.4^{\mathrm{B}}$ & $50.0^{\mathrm{A}}$ & $50.9^{\mathrm{A}}$ & 1.3274 & $<0.0001$ \\
\hline PUFA n-6 & $44.2^{\mathrm{C}}$ & $46.1^{\mathrm{B}}$ & $47.1^{\mathrm{B}}$ & $49.7^{\mathrm{A}}$ & $50.7^{\mathrm{A}}$ & 1.3456 & $<0.0001$ \\
\hline PUFA n-3 & $0.40^{\mathrm{A}}$ & $0.37^{\mathrm{AB}}$ & $0.31^{\mathrm{BC}}$ & $0.29^{\mathrm{C}}$ & $0.27^{\mathrm{C}}$ & 0.0471 & $<0.0001$ \\
\hline PUFA n-6/n-3 & $110^{\mathrm{D}}$ & $125^{\mathrm{CD}}$ & $152^{\mathrm{BC}}$ & $171^{\mathrm{AB}}$ & $188^{\mathrm{A}}$ & 23.9285 & $<0.0001$ \\
\hline
\end{tabular}

$* \mathrm{p}$ value for linear response. The values with different big letters in the same row differ significantly $(\mathrm{p}<0.01)$.

RMSE $=$ Root mean square error. SFAs $=$ Saturated fatty acid; SFAs $(\%)=$ C14:0+C16:0+C17:0+C18:0.

MUFAs $=$ Monounsaturated fatty acid; MUFAs $(\%)=\mathrm{C} 16: 1+\mathrm{C} 18: 1$

PUFAs = Polyunsaturated fatty acid; PUFAs $(\%)=$ C18:2 (n-6)+C18:3 (n-6)+C18:3 (n-3)+C20:2 (n-6)+C20:3 (n-6)+C20:4 (n-6)+C22:4 (n-6)

PUFA n-6 $(\%)=$ C18:2 (n-6)+C18:3 (n-6)+C20:2 (n-6)+C20:3 (n-6)+C20:4 (n-6)+C22:4 (n-6). PUFA n-3 (\%) = C18:3 (n-3).

PUFA n-6/n-3 = PUFA n-6/PUFA n-3.

in the liver was obtained $(\mathrm{p}=0.0081)$ and CPT 1 mRNA expression in the liver in the $1.80 \%$ diet group was the biggest $(p<0.05)$. The differences of ACC mRNA expression in the liver of different treatments were not significant $(\mathrm{p}>0.05)$.

\section{DISCUSSION}

\section{Growth performance}

There were few studies about the effect of dietary varying amounts of LA on growth or production performance of animals and no significant effect was found. In this study, dietary LA supplementation had not significantly affected growth performance of the experimental rabbits. This is in agreement with other studies that found that productive performances were not affected by different treatments (Dal Bosco et al., 2004; Peiretti and Meineri, 2008; Kouba et al., 2008).

\section{Dressing out percentage and meat quality}

Meat quality consists of nutritional properties, sensory characteristics, health and technological factors and is significantly influenced by dietary factors including fatty acids. In this study, dietary LA concentrations had no significant influence on dressing out percentage, $\mathrm{L}^{*}$ of muscle color of LL, $\mathrm{pH}$ value, shear force and drip loss percentage of the experimental rabbits. This is in agreement with other studies that found no significant differences of the carcass weight and dressing percentage and dry matter from rabbits among batches when slaughter weight was $2500 \mathrm{~g}$ (Cobos et al., 1985), the proximate composition of the fresh muscle was not significantly affected by the

Table 7. The effect of dietary linoleic acid on acetyl-CoA carboxylase (ACC) and carnitine palmitoyl transferase 1 (CPT1) mRNA expression in the liver of the experimental rabbits $(n=8)$

\begin{tabular}{lllllllll}
\hline \multirow{2}{*}{ Items } & \multicolumn{9}{c}{ Linoleic acid concentration in the diet (\%) } & \multirow{2}{*}{ RMSE } & \multirow{2}{*}{$\mathrm{p}^{*}$} \\
\cline { 2 - 5 } & 0.84 & 1.21 & 1.34 & 1.61 & 1.80 & & 0.3754 & 0.6435 \\
ACC & 1.11 & 0.73 & 0.92 & 1.01 & 1.08 & 0.3754 & 0.0081 \\
CPT1 & $0.97^{\mathrm{B}}$ & $1.12^{\mathrm{B}}$ & $1.13^{\mathrm{B}}$ & $0.92^{\mathrm{B}}$ & $2.13^{\mathrm{A}}$ & 0.5477 & \\
\hline
\end{tabular}

The values with different big letters in the same row differ significantly $(\mathrm{p}<0.01)$. RMSE $=$ Root mean square error. * $\mathrm{p}$ value for linear response. 
dietary treatment (Dal Bosco et al., 2004), the diets did not significantly influence the carcass yield and the proportion of various carcass parts and organs of the rabbits (Peiretti and Meineri, 2008). On the contrary, Oliver et al. (1997), Bianchi et al. (2006, 2009) found that diet had a significant effect on the $\mathrm{pH}$ of rabbit meat, probably because the results were measured in different post-slaughter time, position and age.

In this study, dietary LA concentrations had significant influence on muscle color of LL included $a^{*}$ and $b^{*}$. This is in agreement with other studies that found that diet had a significant effect on the colour of the Longissimus dosi muscle (Oliver et al., 1997), the meat (L. lumborum) from rabbits fed on diets containing linseed exhibited higher a* values (Bianchi et al., 2006, 2009).

\section{Serum biochemical traits}

As one kind of PUFAs, LA had important influences on blood fat of human beings and animals. A great amount of animal experiments and clinical researches had demonstrated that LA can obviously depressed serum cholesterol and LDL-C levels, and significantly affected lipoprotein metabolism and decreased cardiovascular disease probability.

Lee et al. (1994) assessed the effect of CLA addition (0.5 g CLA/rabbit per day) on blood traits of rabbits and illustrated that TC, LDL-C and TG were markedly lower, the LDL-C to HDL-C ratio and TC to HDL-C ratio were significantly reduced in the CLA-fed group. Newman et al. (2002) investigated the effects of dietary SFA and PUFA of the n-3 and n- 6 series on body composition in broiler chickens and showed that the PUFA-rich diets lowered plasma concentrations of serum TG and cholesterol. Crespo and Esteve-Garcia (2003) showed that broilers fed diets rich in SFA have higher levels of serum VLDL than those fed diets rich in PUFA. In this study, dietary LA addition increased serum HDL-C concentration and had no significant influence on serum TG, TC, LDL-C and VLDL$\mathrm{C}$ concentration of experimental rabbits. Rabbits are able to recycle part of the end microbial fermentation products through cecotrophy (Gomez-Londe et al., 2006), so it is important that the possible formation of CLA from LA in the large intestine because of cecotrophy and the effects of CLA addition in the diets on blood traits were bigger than those of LA addition in the diets. Meanwhile, the different research results may be related to PUFA types and doses, animal species and animal growth stages.

\section{Fatty acids composition in the muscle and liver}

Since manipulation of the rabbit diet is very effective in increasing the levels of n-3 PUFA or CLA, there were numerous studies dealing with the use of polyunsaturated fatty acid (PUFA) rich diet in rabbits and its effect on fatty acid composition of rabbit meat and fat (Borgman, 1964; Ahluwalia et al., 1967; German, 1990; Gondret et al., 1998; Dal Bosco et al., 2004; Bianchi et al., 2006; Kouba et al., 2008; Peiretti and Meineri, 2008; Tres et al., 2008; Bianchi et al., 2009), and illustrated that the use of PUFA rich diet in rabbits may increased the PUFA especial n-3 PUFA contents and decreased SFA contents.

In this study, the SFAs contents in the LL and MUFAs contents in the LL and liver decreased with dietary LA increase, and the PUFAs content in the LL and liver increased with dietary LA increase. This is in agreement with above studies that found the use of PUFA rich diet in rabbits may increased the PUFA especial n-3 PUFA contents and decreased SFA contents. But, in this study, dietary LA addition increased the PUFA $n-6$ content and PUFA n-6/n-3 in the LL and liver. Although the increase of PUFAs contents in the muscle and liver may be benefit to human being, the excessive amounts of n-6 PUFA and a very high n-6/n-3 ratio, as is found in today's Western diets, promote the pathogenesis of many diseases, including cardiovascular disease, cancer, and inflammatory and autoimmune disease (Simopoulos, 2008). So, the dietary LA addition was not favourable from a nutritional point of view.

In this study, the arachidonic acid (C20:4 n-6) contents in the LL and liver increased by the increasing dietary level of LA, this is in agreement with other results that found that the C20: 4 n- 6 contents of rabbit meat or rabbit meat hamburgers were affected by different diets (Lopez-Bote et al., 1997; Peiretti and Meineri, 2008; Bianchi et al., 2009). On the contrary, many studies found that diet had not significantly affected the C20:4 n-6 contents in rabbit meat (Cobas et al., 1995; Dal Bosco et al., 2004; Bianchi et al., 2006; Kouba et al., 2008). This difference may be due to the differences of dietary fatty acid composition.

\section{Acetyl-CoA carboxylase and carnitine palmitoyl transferase $1 \mathrm{mRNA}$ expression in the liver}

To date, it had been confirmed that many enzymes related to fatty acid synthesis were manipulated by PUFA, such as ACC and fatty acid synthetase (FAS) and so on. But, the reports about manipulation of dietary PUFA on CPT were scare. ACC is a key enzyme of synthesized long chain fatty acids. Many researches illustrated that the ACC expression may be degressed by dietary PUFAs. Bing et al. (1996) pointed that lipogenic gene transcription is inhibited by PUFA and illustrated that the suppression of hepatic lipogenesis is due, at least in part, to an inhibition of transcription of several genes encoding proteins involved in both lipogenesis and glycolysis, including fatty acid synthase, stearoyl-CoA desaturase, L-type pyruvate kinase, and the S14 protein. Yahagi et al. (1999) also demonstrated that the ACC expression in the mice may be depressed by 
dietary PUFAs. But, dietary LA addition had no influenced ACC mRNA expression in the liver of experimental rabbits in this study.

Chatelain et al. (1996) reported that the rapid increase in hepatic CPT I mRNA level that accompanies the fetal to neonatal transition in the rat is triggered by the reciprocal change in circulating insulin and long chain fatty acid concentrations. In this study, dietary LA addition of experimental rabbits also increased CPT 1 mRNA expression in the liver. This stated that LA can significantly enhance lipid $\beta$-oxidation of animal and lower fat synthesis.

In conclusion, dietary LA addition significantly affected liver and muscle fatty acid composition, especially increased PUFAs content, but had little effects on growth performance and meat physical traits of 9 wks old to 13 wks old growing meat rabbits. From a nutritional point of view, PUFA n-6 and PUFA n-6/n-3 ratio increase are not favourable. The results also indicate that LA affects liver CPT 1 mRNA expression. One potential mechanism of how LA may improve fatty acid composition of growing rabbits is through increasing the synthesis and secretion of CPT 1 .

\section{ACKNOWLEDGEMENTS}

The work was supported by the earmarked fund for Modern Agro-industry Technology Research System (CARS-44-B-1) and the Special Fund for Agro-scientific Research in the Public Interest (2000903006).

\section{REFERENCES}

Ahluwalia, B., G. Pincus and R. T. Holman. 1967. Essential fatty acid deficiency and its effects upon reproductive organs of male rabbits. J. Nutr. 92:205-214.

Bianchi, M., M. Petracci and C. Cavani. 2006. Effects of dietary inclusion of dehydrated lucerne and whole linseed on rabbit meat quality. World Rabbit Sci. 14:247-258.

Bianchi, M., M. Petracci and C. Cavani. 2009. The influence of linseed on rabbit meat quality. World Rabbit Sci. 17:97-107.

Bing, R., A. Thelen and D. B. Jump. 1996. Peroxisome proliferator-activated receptor $\alpha$ inhibits hepatic s14 gene transcription evidence against the peroxisome proliferatoractivated receptor $\alpha$ as the mediator of polyunsaturated fatty acid regulation of s14 gene transcription. J. Biol. Chem. 271: 17167-17173.

Blasco, A. and J. Ouhayoun. 1993. Harmonization of criteria and terminology in rabbit meat research. Revised proposal. World Rabbit Sci. 4:93-99.

Borgman, R. F. 1964. Fatty acid composition as influenced by dietary fatty acids and vitamin E status in the rabbit. J. Food Sci. 29:20-24.

Cavani, C., M. Petracci, A. Trocino and G. Xicatto. 2009. Advances in research on poultry and rabbit meat quality. Ital. J. Anim. Sci. 8 (Suppl. 2):741-750.

Chatelain, F., C. Kohl, V. Esser, J. Denis Mcgarry, J. Girard and J. P. Pegorier. 1996. Cyclic AMP and fatty acids increase carnitine palmitoyltransferase 1 gene transcription in cultured fetal rat hepatocytes. Eur. J. Biochem. 235:789-798.

Cobos, A., L. de la Hoz, M. I. Cambero and J. A. Ordonez. 1995. Sugar-beet pulp as an alternative ingredient of barley in rabbit diets and its effect on rabbit meat. Meat Sci. 39:113-121.

Corino, C., J. Mourot, S. Magni, G. Pastorelli and F. Rosi. 2002. Influence of dietary conjugated linoleic acid on growth, meat quality, lipogenesis, plasma leptin and physiological variables of lipid metabolism in rabbits. J. Anim. Sci. 80:1020-1028.

Corino, C., F. Filetti, M. Gambacorta, A. Manchisi, S. Magni, G. Pastorelli, R. Rossi and G. Maiorano. 2003. Influence of dietary conjugated linoleic acids (CLA) and age at slaughtering on meat quality and intramuscular collagen in rabbits. Meat Sci. 66:97-103.

Crespo, N. and E. Esteve-Garcia. 2003. Polyunsaturated fatty acids reduce insulin and very low-density lipoprotein levels in broiler chickens. Poult. Sci. 82:1134-1139.

Dal Bosco, A., C. Castellini, L. Bianchi and C. Mugnai. 2004. Effect of dietary $\alpha$-linolenic acid and vitamin $\mathrm{E}$ on the fatty acid composition, storage stability and sensory traits of rabbit meat. Meat Sci. 66:407-413.

Datte Zotte, A. 2002. Perception of rabbit meat quality and major factors influencing the rabbit carcass and meat quality. Livest. Prod. Sci. 75:11-32.

Dalle Zotte, A. and Z. Szendro. 2011. The role of rabbit meat as functional food. Meat Sci. 88:319-331.

de Blas, C. and G. G. Mateos. 1998. Feed formulation. In: The Nutrition of the Rabbit (Ed. C. de Blas and J. Wiseman). CABI Publishing, New York, NY, USA, pp. 241-253.

Folch, J., M. Lees and G. H. Sloane Stanley. 1957. A simple method for isolation and purification of total lipids from animal tissues. J. Biol. Chem. 226:497-509.

German, J. B. 1990. Muscle lipids. J. Muscle Foods 1:339-361.

Gomez-Londe, M. S., D. Menoyo, S. Chamorro, C. J. Lopez-Bote, P. Garcia-Rebollar and J. C. de Blas. 2006. Conjugated linoleic acid content in coecotrophes, suparenal and intramuscular fat in rabbit fed commercial diets. World Rabbit Sci. 14:95-99.

Gondret, F., J. Mourot, F. Lebas and M. Bonneau. 1998. Effects of dietary fatty acids on lipogenesis and lipid traits in muscle, adipose tissue and liver of growing rabbits. Anim. Sci. 66: 483-489.

Kouba, M., F. Benatmane, J. E. Blochet and J. Mourot. 2008. Effect of a linseed diet on lipid oxidation, fatty acid composition of muscle, perirenal fat, and raw and cooked rabbit meat. Meat Sci. 80:829-834.

Lee, K. N., D. Kritchevsky and M. W. Pariza. 1994. Conjugated linoleic acid and atherosclerosis in rabbits. Atherosclerosis 1: 19-25.

Lopez-Bote, C., A. I. Rey, M. Sanz, I. Gray and J. Buckley. 1997. Dietary vegetable oils and $\alpha$-tocopherol reduce lipid oxidation in rabbit muscle. J. Nutr. 127:1176-1182.

Newman, R. E., W. L. Bryden, E. Fleck, J. R. Ashes, W. A. Buttemer and L. H. Storlien. 2002. Dietary n-3 and n-6 fatty acids alter avian metabolism and abdominal fat deposition. Br. J. Nutr. 88:11-18.

NRC. 1977. Nutrient Requirements of Domestic Animals, No.9. Nutrient requirements of rabbits. Second Revised Ed. National Academy of Sciences-National Research Council, Washington, DC, USA. 
Oliver, M. A., L. Guerrero, I. Diaz, M. Gispert, M. Pla and A. Blasco. 1997. The effect of fat-enriched diets on the perirenal fat quality and sensory characterstics of meat from rabbit. Meat Sci. 47:95-103.

Ouhayoun, J. and A. Dalle Zotte. 1996. Harmonization of muscle and meat criteria in rabbit meat research. World Rabbit Sci. 4: 211-218.

Peiretti, P. G. and G. Meineri. 2008. Effects on growth performance, carcass characteristics, and the fat and meat fatty acid profile of rabbits fed diets with chia (Salvia hispanica L.) seed supplements. Meat Sci. 80:1116-1121.

SAS, 1985. Users guide: Basics. SAS Institute, Cary, NC, USA.

Simopoulos, A. P. 2008. The importance of the omega-6/omega-3 fatty acid ratio in cardiovascular disease and other chronic diseases. Exp. Biol. Med. 233:674-688.
Tres, A., R. Bou, R. Codony and F. Guardiola. 2008. Influence of dietary doses of n-3- or n-6-rich vegetable fats and $\alpha$-tocopheryl acetate supplementation on raw and cooked rabbit meat composition and oxidative stability. Agric. Food Chem. 56:7243-7253.

Xiccato, G. 1999. Feeding and meat quality in rabbits: a review. World Rabbit Sci. 7:75-86.

Yahagi, N., H. Shimano, A. H. Hasty, M. Amemiya-Kudo, H. Okazaki, Y. H. Tamura, F. Shionoiri, K. Ohashi, J. Osuga, K. Harada, T. Gotoda, R. Nagai, S. Ishibashi and N. Yamada. 1999. A crucial role of sterol regulatory element-binding protein-1 in the regulation of lipogenic gene expression by polyunsaturated fatty acids. J. Biol. Chem. 274:35840-35844. 